\title{
Medico legal issues in necrophilia and other related matters
}

\author{
Ariyarathna $\mathrm{HTDW}^{1^{*}}$
}

\begin{abstract}
Introduction: Necrophilia is an area that is not much discussed in our country. It may prevent the required thinking on this regard during the medico legal examination and in other practical issues. As such necrophilia is a topic about which a comprehensive understanding is essential not to miss any related issues. Objectives: Post mortem injuries or effects which had been added after death which raise totally different medico legal issues during the investigation. Had the pathologist not suspected about necrophilic action, he would not have examined the oral and anogenital regions specifically. In such a situation, the possibility of necrophilic acts may go unnoticed. Additionally the views of the public that the necrophilic acts could secretly occur at the hands of funeral directors should be considered, as the public is rather confused or do not expect happening of such disgraceful acts. Discussion: Unless there is a list of well foreseen medico legal issues, the procedure of the post mortem does not aim into certain possibilities. The same applies in the context of sample collection. As the necrophilia is a rare occurrence, the routine medico-legal examination may pass necrophilic actions unnoticed unless they are objectively investigated. Conclusion: The possibility of necrophilic actions always should be excluded in homicidal dead bodies when it is indicated by the examining pathologist. The possible necrophilic acts that could occur at the hands of funeral directors should also not be overlooked. Making amendments to the Sri Lankan law should be considered to encompass this offence.
\end{abstract}

Key words: necrophilia, legality, funeral directors

\section{Introduction}

Medico legal investigation in a case of homicide is a judicious process. A competent pathologist should address all the possible circumstances related to a particular incident at the time of the initial post mortem. The court room is a place where strange and unforeseen medico-legal issues are raised during the examination-in-chief and in cross-examination. Having sexual acts with dead people is such a possibility though it appears to be rare. As such suspicion of necrophilic acts (even with trivial alarming) during the medico legal examination enhances the completeness of the investigation. In addition to the aforesaid academic context, it came to know that the public was suspicious about necrophilic acts/sexual intercourse after handing over the dead bodies to the funeral directors in certain

Senior lecturer, Department of Forensic Medicine, Faculty of Medical Sciences, University of Sri Jayewardenepura, Gangodawila, Nugegoda

*Corresponding author: Ariyarathna HTDW, Tele: 011 2758607, e-mail address: weerawickramers@hotmail.com areas. (Personal communication) The following analysis attempts to raise few important points related to necrophilia that would be helpful in the medico legal field.

\section{Discussion}

Legends with necrophilic themes are not rare as it has a long history, extending far back up to the ancient Egyptians. [1] As the act would be procured secretly from a victim unable to complain, it is somewhat difficult to diagnose unless an additional suspicion is raised.

\section{Necrophilia and its classification}

Necrophilia is categorized under the section paraphilia. [2] The definition of paraphilia is highly controversial over the years and still it seems to be continuing. One of the widely accepted definitions would suggest it as follows: In the DSM-IV and DSM-IV-TR, the essential features of a Paraphilia are recurrent, intense sexually arousing fantasies, sexual urges or behaviors generally involving nonhuman objects, the suffering or humiliation of oneself or one's partner, or children or other non-consenting persons that occur over a period of at least 6 months. (Criterion A). [3] 
According to the Professor Stephen Hucker (a Consulting Forensic Psychiatrist) at the University of Toronto "the necrophilia is best defined as sexual arousal stimulated by a dead body and the stimulation can be either in the form of fantasies or actual physical sexual contact with the corpse". The DSMIV-TR criteria for necrophilia are the presence, over a period of at least six months, of recurrent and intense urges and sexually arousing fantasies involving corpses which are either acted upon or have been markedly distressing. [4]

It may appear that necrophilia is simple to be defined. But a broad spectrum of necrophilicbehaviours has been identified. The simplest being fantasies alone and the most severe is the killing of people for the sake of procuring a dead body.

The following sub categorization (which is ten-tier classification) is published by Anil Aggrawal, as he thinks it needs unanimity in the classification. [2, 5]

Class I necrophiliacs: "Role players": People who get aroused from pretending their live partner is dead during sexual activity, but never actually have sex with a corpse.

Class II necrophiliacs: "Romantic necrophiliacs": Bereaved people who remain attached to their dead lover's body and they still don't want to accept the truth that the loved person is already dead. They have very mild necrophilic tendencies.

Class III necrophiliacs: "Necrophilic fantasizers": Simply fantasize about having sexual contact with dead people but never actually engage in the activity for real. Such people may become sexually aroused when seeing dead people and may engage in activities that increase their likelihood of seeing the dead.

Class IV necrophiliacs: "Tactile necrophiles": Who erotically touch dead bodies to achieve orgasm. They seek out jobs in which they come into regular contact with the dead (e.g., mortuary assistants) and they "enjoy touching, stroking parts of the dead body, such as genitalia or breasts or perhaps licking them" Class V necrophiliacs: "Fetishistic necrophiliacs": They do not have sexual intercourse with dead people but will (if the chance arises) "cut up some portion of the body, perhaps a breast, for later fetishistic activities" or may "keep some portion of the dead body - pubic hair or a finger perhaps - in the pocket for continuous erotic stimulation, or sometimes may wear it as an amulet for similar pleasure".

Class VI necrophiliacs: "Necromutilomaniacs": They do not engage in sexual intercourse with dead people but gain sexual pleasure from masturbation while simultaneously mutilating dead bodies. Included within this type of necrophile are those who get sexual pleasure from eating part of the corpse (i.e. necrophagy).

Class VII necrophiliacs: "Opportunistic necrophiliacs": They are the people that typically engage in 'normal' sexual behaviour but would have sexual intercourse with a dead person "if an opportunity arose"

Class VIII necrophiliacs: "Regular necrophiliacs": This type comprises regular necrophiles who according to Aggrawal are the "classical" necrophiliacs as most people would understand. Aggrawal claims that this type of necrophile doesn't enjoy sexual intercourse with people who are alive and has a distinct preference for sexual activity with the dead. Regular necrophiles will go to extreme lengths to engage in their sexual preference including stealing dead bodies from graveyards or mortuaries. Class IX necrophiliacs: "Homicidal necrophiliacs": (the behaviour of which is sometimes referred to as homicidophilia or 'lust murder') According to Aggrawal they are the most dangerous type of necrophile (and are sometimes referred to as 'necrosadists'). These people will go as far as killing people just so as they can have sex with the dead. Aggrawal also says that the behaviour may be described as "warm necrophilia" because sex typically takes place immediately after the killing while the bodies are still warm.

Class X necrophiliacs: "Exclusive necrophiliacs": This type comprises the rarest necrophile sub-type. These people are psychologically and physiologically incapable of having sex with the living and therefore are only capable of having sex with the dead. Aggrawal claims that because dead bodies are the prerequisite for sexual behaviour to occur, the person may go to any lengths to acquire a dead body.

With the above description it is obvious that necrophilia is not simple as one would imagine. Suspecting acts of necrophilia could be fairly easy in class VIII and above, but when it comes to the lesser degrees than that, it may not be easy to diagnose and even may be beyond successful proving with the routine medico legal investigation.

\section{Medico legal investigation}

Medico legal investigation involves examination of scene/s, examination of the dead body and examination of the suspect/s with the help of respective experts. 
The examination of the alleged crime scene may end up later with multiple scene examinations and investigation should be directed accordingly. Other than the routine and ancillary procedures, one of the greatest concerns of the pathologist is to confirm or refute the suspicion of whether the corpse was sexually abused or not. This is basically resolved by determining whether the injuries are ante-mortem, post-mortem or peri-mortem. Multiple bite marks and mutilation of the body are also possible at times. The histopathological examination would differentiate the nature of the injuries while the histochemical studies would date the injuries. If the body is anally penetrated, anal dilatation is a possibility, though it is a common post mortem phenomenon. But presence of anal dilatation, with the rigor mortis in other parts of the body is assumed as a suggestive evidence of necrophilic action. [5] DNA profiling including Touch DNA (skin cells left on an object after it has been touched or casually handled [6]) and investigations with finger prints bear a significant place in exclusion/inclusion of suspects. Any evidence of missing cloths such as bra, panties and clipped pubic hair etc. has to be inspected as those may be removed for fetishistic activities.

Whenever necrophiliacs are suspected, the examination of the suspect, if available is an essential requirement. With the routine investigative methods, evaluation his/her psychological assessment is a prerequisite. In addition to this, the examination of the suspect's belongings (as there may be clues) including his computers (computer forensic) is also warranted. If available, it is worth while performing the Deception Detection Tests (DDT) such as polygraph, narco-analysis and brain-mapping. [7]

\section{Legal issues}

Expert testimony of several specialists such as pathologist, psychiatrist, forensic scientist, and police is a requirement to continue a successful prosecution. There may be many arguments at the court rooms in relation to a case of necrophilia. Having intercourse or other sexually related activities with dead is not rape or grave sexual abuse as these acts had not been inflicted on live persons. So there could be two folds arguments by the defense and the prosecution. Theprosecutionwould give evidence that the sexual intercourse/acts were performed during the life and after that the female was killed raising the issue of rape and murder. In contrast to that, the defense would argue to prove that the defendant only had sex with the dead body as it imposes a far less severe sentence on the defendant for being only a necrophile. The pathologist should have sound and firm findings to either refuse or accept the arguments raised during the court hearings when it is questioned at the courts.

Furthermore, there may be numerous acts which can be accommodated under the first seven categories of necrophilia subtypes as described above, with inability to be proven medically, such as touching or kissing a of a dead body etc.

As a result it is a prerequisite to investigate medically at the time of postmortem, whether an act of necrophilia is a possibility, as he or she has to provide his/her expert evidence if an opinion is requested in this direction.

In addition to this, the grievances or suspicions of the public about funeral directors such as an embalmer of the dead bodies etc., whether they had abused the dead bodies or not before the dead bodies are handed over to them are also valid facts that should be addressed in a prudent way.

When it comes to the legislations, specific laws against sexual activities with corpses have not been directly identified in most nations including Sri Lanka. Canada, France, South Africa and United Kingdom are a few countries in which the necrophilia is directly recognized with criminality.[5] In many other countries the explicit recognition is not entertained though it has been criminalized with many other entities under the misconduct to the human remains and so on.

But according to the Sri Lankan law there are a few places where the dignity of a dead body is recognized.

(a) Under the Penal Code of Sri Lanka [8]

According to the interpretations of the Penal Code, the word "person" includes any company or association or body of persons, whether incorporated or not. As a result under the Acts of gross indecency between persons (section 365A), necrophilic actions would be categorized as a criminal offence. Trespassing on burial place (section 292), causing indignity to any human corpse.

(b)The Cemeteries and Burials Ordinance. (An Ordinance to consolidate the law relating to Cemeteries and Burial grounds). [9] Section 14 Corpse not to be removed without authority. Section 28 -Penalty for damaging the Cemetery.

\section{Ethical issues}

There are two broad categories of those who think that necrophilia is ethically correct (pro-necrophiles) 
and those who do not (anti-necrophiles) and they have their own respective arguments.[5] With the hedonistic view point, as it is based on pleasure but nothing else, it may be correct. Whatever the beliefs that people may entertain, the ethical aspects of necrophilia are far from what is discussed here.

Anyhow, it is obvious from the above description that it is only the two subgroups of IX and X that tend to kill a person to procure sex with dead bodies. As such, is it how far ethical to suspect about indulged necrophilic acts on certain dead bodies in order to examine the anogential regions in detail? But on the other hand the defenses able to put forward any opinion in order to create a reasonable suspicion about the opinions provided by the pathologist, highlighting the inadequacy of his investigative procedures. Moreover the credibility of the investigative procedure would also be challenged if a pathologist is unable to evidentially support his opinion either to include or exclude necrophilic act/s. On the other hand, the suspicion about the public regarding the possibility of necrophilic acts at the hands of funeral directors is also should be addressed. The mere fact of keeping the dead bodies for much longer hours than expected at the florists would not attribute solely on this possibility. Converse to this, some researches have proven that the people with necrophilic personalities, are more in favour to choose their occupation to have an access to dead bodies. [10]

\section{Conclusion}

It is mandatory to determine the timing of sexual acts whether they are ante mortem, post mortem or perimortem or as undetermined, as each entity has its own characteristic medicolegal issues as described. It is only the suspicion of necrophillic acts that would persuade a pathologist in further forensic investigation. But on the other hand the ethical issues related to the "over investigation and examination" are also facts that need to be considered. Awareness among the public of such acts is also important in the context of the prevention and also in directing the alleged assailants for treatment. Finally the law also has to be amended so as to cover specific offence/s related to necrophilia.

\section{Recommendations}

Pathologists should be mindful of a possibility of acts of necrophilia when it is suggestive during the medico legal examination. In addition to this, when it is questioned regarding necrophilic actions at the court hearings, the medical opinion better to be comprehensive within his limits of examination.

The ongoing suspicion among the public related with the possibility of necrophillic acts when the dead bodies are handed over to a funeral directors should be considered.

A practical mechanism to safeguard the rights of a dead person and next of kin is also highly advised. It is advisable in specific recognition of necrophilia when amending the Sri Lankan law in the future.

\section{References}

1. Klaf FS, Brown W. Necrophilia, brief review and case report. Article, Psychiatric Quarterly. December 1958, Volume 32, Issue 4, pp 645-652. http://link.springer.com/article/ $\quad 10.1007 \quad \%$ 2FBF01563024. (last accessed 23-03-2016)

2. Aggrawal A.J Forensic Leg Med. 2009 Aug; 16(6):31620. Doi: 10.1016/j.jflm.2008.12.023.

3. Kafka MP, The DSM diagnostic criteria for paraphilia not otherwise specified. Archives of Sexual Behavior. 2010 April; 39(2):373-6. Doi: 10.1007/s10508-009-9552-0

4. American Psychiatric Association, ed. (2013). "Other Specified Paraphilic Disorder, 302.89 (F65.89)". Diagnostic and Statistical Manual of Mental Disorders, Fifth Edition. American Psychiatric Publishing. P. 705. http://www.forensicpsychiatry.ca/paraphilia/necro.htm

5. Aggrawal A. Necrophilia: Forensic and Medico-legal Aspects. Boca Raton: CRC Press; 2011

6. Lepchitz J. Your DNA Could Be Where You Weren't. Richmond Journal of Law and Technology. November 17, 2015. http://jolt.richmond.edu/index.php/your-dnacould-be-where-you-werent/. (Last accessed on 25-032016)

7. Suresh Bada Math. Supreme Court judgment on polygraph, narco-analysis \& brain-mapping: A boon or a bane. Indian Journal of Medical Research. 2011 Jul; 134(1):

4-7. http://www.ncbi.nlm.nih.gov/pmc/articles/PMC3171915/. ( Last accessed on25-03-2016)

8. Penal Code of Sri Lanka (Penal Code (Amendment) act no.22 of 1995)

9. Cemeteries and Burial Grounds Ordinance No 09 of 1899, Sri Lanka

10. Rosman JP, Resnick PJ. Sexual Attraction to Corpses: A Psychiatric Review of Necrophilia. Bulletin of the American Academy of Psychiatry and the Law. 1989; 17 (2): 153-163. http://www.jaapl.org/content/17/2/153.full.pdf (Last accessed on 25-03-2016) 